\title{
Sinterização ultrarrápida por micro-ondas do compósito mulita-cordierita
}

\author{
(Microwave fast sintering of mullite-cordierite composite) \\ G. L. de Gouveia, P. M. de Souto, R. H. G. A. Kiminami \\ Departamento de Engenharia de Materiais, Universidade Federal de S. Carlos \\ Rod. Washington Luis, km 235, S. Carlos, SP 13565-905 \\ pollyanesouto@yahoo.com.br,ruth@ufscar.br
}

\begin{abstract}
Resumo
A sinterização ultrarrápida por micro-ondas é uma técnica que oferece enorme potencial para a fabricação de diversos materiais cerâmicos com microestruturas cerâmicas diferenciadas. Assim, este trabalho teve por objetivo sinterizar compósitos cerâmicos do tipo mulita-cordierita em forno de micro-ondas. Para realizar essa pesquisa, foi utilizado um compósito $60 \%$ mulita- $40 \%$ cordierita, originário da empresa Scimarec Co. Amostras desse compósito foram sinterizadas em forno convencional e por sinterização ultrarrápida em forno de micro-ondas. A caracterização foi feita por difratometria de raios X, microscopia eletrônica de varredura e determinação de densidade aparente. A sinterização ultrarápida do compósito por micro-ondas foi realizada em menos de $10 \%$ do tempo gasto para realizar a sinterização convencional e apresentou mesmos mecanismos de sinterização com potencia e tempo controlados.
\end{abstract}

Palavras-chave: sinterização, mulita, mulita-cordierita, cordierita, micro-ondas.

\begin{abstract}
Microwave fast sintering is a technique with a huge potential for the manufacture of a variety of ceramic materials with controlled ceramic microstructures. The objective of the present work was the microwave fast sintering of mullite-cordierite type ceramic composites in a microwave oven and to examine the influence of power and sintering time on the material. In this research, we used an industrial $60 \%$ mullite-40\%cordierite composite. Samples of the composite were sintered by the conventional and microwave routes, after which they were characterized by X-ray diffraction and scanning electron microscopy, and their density determined. The microwave fast sintering process took less than $10 \%$ of the time required for conventional sintering and showed the same sintering mechanisms with power and time controlled.
\end{abstract}

Keywords: sintering, mullite, mullite-cordierite, cordierite, microwaves.

\section{INTRODUÇÃO}

A mulita, única fase cristalina estável no sistema $\mathrm{Al}_{2} \mathrm{O}_{3}-$ $\mathrm{SiO}_{2}$ desde a temperatura ambiente até, aproximadamente, $1800^{\circ} \mathrm{C}$ sob pressão atmosférica [1], cuja composição química é variável sobre a faixa de $3 \mathrm{Al}_{2} \mathrm{O}_{3} \cdot 2 \mathrm{SiO}_{2}$ a $2 \mathrm{Al}_{2} \mathrm{O}_{3} \cdot \mathrm{SiO}_{2}$, vem sendo progressivamente pesquisada e utilizada devido ao seu conjunto característico de propriedades, dentre as quais se destacam: excelente resistência à fluência e ao choque térmico, boa refratariedade e boa inércia química, além de sua baixa densidade $\left(3,18 \mathrm{~g} / \mathrm{cm}^{3}\right)$. Ela se assemelha a outras cerâmicas cristalinas com alto grau de ligação covalente, nas quais temperaturas relativamente altas são necessárias para sua densificação [2]. Por sua vez, a fase cordierita é um aluminossilicato de magnésio $\left(2 \mathrm{MgO} .2 \mathrm{Al}_{2} \mathrm{O}_{3} .5 \mathrm{SiO}_{2}\right)$ cristalino do sistema $\mathrm{MgO}-\mathrm{Al}_{2} \mathrm{O}_{3}-\mathrm{SiO}_{2}$ [3]. A excelente resistência ao choque térmico é a sua principal característica, produto do seu baixo coeficiente de expansão térmica em uma ampla faixa de temperatura, de 0,5 a $4,0 \times 10^{-6}{ }^{\circ} \mathrm{C}^{-1}$ [4]. Esse aspecto está relacionado ao fato de a cordierita ter uma estrutura cristalina bastante aberta, capaz de absorver as variações atômicas de expansão-retração, advindas das variações bruscas de temperatura [5]. O compósito mulita-cordierita vem atuando intensivamente nas aplicações onde sua baixa expansão térmica e sua baixa constante dielétrica são necessárias, principalmente na substituição da alumina e substratos cerâmicos [6]. Por exemplo, no setor automotivo, vem se substituindo o suporte catalítico de cordierita por suportes de mulita-cordierita devido ao fato de este apresentar maior resistência mecânica. A grande dificuldade em muitos estudos está na densificação do compósito, principalmente, abaixo do intervalo de $1410^{\circ} \mathrm{Ca} 1425^{\circ} \mathrm{C}$, onde ocorre a formação de uma fase líquida devido à interação de $\mathrm{MgO} \operatorname{com~} \mathrm{SiO}_{2}$ presentes na fase cordierita. Ao exceder este ponto, tem início o mecanismo de sinterização com fase líquida, fator que proporciona uma maior densificação, devido à alteração da cinética do processo de sinterização, e uma melhora das propriedades mecânicas [7]. O MgO, presente na fase cordierita, aumenta a densificação da fase mulita [8] através da desestabilização da composição química da zona próxima ao contorno do grão de mulita, induzindo à mudança da composição $2 \mathrm{Al}_{2} \mathrm{O}_{3} \cdot \mathrm{SiO}_{2}$ para $3 \mathrm{Al}_{2} \mathrm{O}_{3} .2 \mathrm{SiO}_{2} ;$ o $\mathrm{SiO}_{2}$ excedente forma uma fase líquida com o $\mathrm{MgO}$ na região do contorno do grão. Este processo de desestabilização seguido da formação de uma fase líquida de 
composição $\mathrm{MgO}-\mathrm{SiO}_{2}$ ocorre até o momento em que todo o $\mathrm{MgO}$ forme fase líquida, podendo chegar a uma configuração na qual existe uma camada de alumina em volta do grão de mulita [7]. A formação dessa fase líquida, de acordo com o diagrama de fases $\mathrm{Al}_{2} \mathrm{O}_{3} \cdot \mathrm{SiO}_{2} \cdot \mathrm{MgO}$, ocorre por volta de $1410{ }^{\circ} \mathrm{C}$ a $1425^{\circ} \mathrm{C}$ e atua no melhoramento da densificação da mulita pelo aumento do coeficiente de difusão no contorno do grão, devido à mudança de composição superficial e pela cinética dos mecanismos de sinterização relacionados à sinterização com fase líquida. Hodge [6] verificou que um aspecto microestrutural comum em todas as suas amostras de mulita-cordierita foi a presença de poros grosseiramente esféricos, geralmente distribuídos uniformemente através do compósito, limitando assim a densidade do compósito para aproximadamente $94 \%$ da densidade teórica. Por meio de várias análises o autor concluiu que a porosidade residual observada é resultante do fato que a cordierita fundida não molha completamente a superfície dos cristais de mulita e que os poros acumulam volume de gás circundado pelo silicato líquido, devido à baixa tensão superficial típica que os silicatos apresentam, na ordem de 200 a $400 \mathrm{dyna} / \mathrm{cm}$. Vale a pena salientar que os estudos acima mencionados foram realizados em condições normais de sinterização, e o trabalho desenvolvido analisou os mesmos efeitos dos mecanismos em sinterização em micro-ondas, sobre o que, até o momento, não foi evidenciada nenhuma literatura. No processamento térmico convencional ocorre inicialmente o aquecimento da superfície do material e só em seguida, através de processos de convecção e condução, a energia térmica é transferida para o interior do corpo cerâmico. Em contraste, a energia de micro-ondas é transformada em calor diretamente dentro do material, através da interação das moléculas e átomos com o campo eletromagnético, o que possibilita o aquecimento interno e volumétrico, provocando a formação de gradientes de temperaturas e fluxos de calor invertidos, comparativamente ao processo de aquecimento convencional [9-14]. Essas características permitem o aquecimento de peças grandes de maneira rápida e uniforme, sem a geração de elevadas tensões térmicas que podem causar trincas ou danos às peças. $\mathrm{O}$ aquecimento auxiliar na sinterização ultrarrápida híbrida por micro-ondas, com a utilização de materiais susceptores, mostrou-se extremamente eficiente no processamento de cerâmicas com baixas perdas dielétricas ou com propriedades dielétricas complexas e extremamente difíceis de sinterizar. Na grande maioria dos casos o uso de susceptores tornou-se fundamental para a queima rápida dos materiais cerâmicos. Esta forma de aquecimento mostra ser vantajosa por varias maneiras, dentre as quais podemos destacar: rapidez de processamento (devido à eliminação do tempo necessário para que ocorra o aquecimento do material sem a formação de tensões que possam levar ao choque térmico), homogeneidade de temperatura no material durante o processamento e, principalmente, a possibilidade de obtenção de uma microestrutura específica de forma homogênea por todo o volume da peça. Sutton [15] ainda destaca como benefícios causados pela utilização das microondas, em relação ao modo convencional, no processamento os seguintes itens: redução de custos (tempo e energia, espaço reduzido), aquecimento rápido, aquecimento seletivo controlado (dependente da constante dielétrica do material), redução de emissões perigosas, rendimentos de produto aumentados, diminuição de poluição (limpo e silencioso). Assim, neste contexto, este trabalho tem por objetivo a sinterização ultrarrápida do compósito mulita-cordierita por micro-ondas.

\section{MATERIAIS E MÉTODOS}

O material utilizado no estudo foi um pó comercial do compósito mulita-cordierita proveniente da Scimarec Co., Japão, cuja composição é $60 \%$ mulita e $40 \%$ cordierita, cuja densidade, determinada a partir do picnômetro a hélio, foi $3,13 \mathrm{~g} / \mathrm{cm}^{3}$. Inicialmente o pó foi submetido à desaglomeração em meio alcoólico durante $1 \mathrm{~h}$, obtendo assim um tamanho médio de partículas primárias de 2,4 $\mu \mathrm{m}$. Posteriormente, o pó foi secado com ar comprimido. As amostras foram conformadas por prensagem uniaxial a 80 $\mathrm{MPa}$, seguida de prensagem isostática a $200 \mathrm{MPa}$ na forma de pastilhas com $11 \mathrm{~mm}$ de diâmetro e 3,3 $\mathrm{mm}$ de espessura. As amostras foram sinterizadas convencionalmente e por sinterização ultrarrápida em forno de micro-ondas. O método de sinterização em forno convencional (Lindberg/Blue) foi com uma taxa de aquecimento fixa de $5{ }^{\circ} \mathrm{C} / \mathrm{min}$ até $1300^{\circ} \mathrm{C}$, $1350^{\circ} \mathrm{C}, 1400^{\circ} \mathrm{C}, 1450^{\circ} \mathrm{C}$ e $1500^{\circ} \mathrm{C}$, e com patamar de $2 \mathrm{~h}$. A sinterização ultrarrápida por micro-ondas foi com uma taxa de aquecimento em $\sim 70^{\circ} \mathrm{C} / \mathrm{min}$ em um forno Cober Eletronics Inc., com frequência de $2,45 \mathrm{GHz}$ e com variação de tempo de sinterização de 20 e 30 min e potência de $1,2 \mathrm{~kW}, 1,5 \mathrm{~kW}$, $1,8 \mathrm{~kW}$ e 2,1 kW. As medidas de densidade aparente (DA) das amostras sinterizadas foram pelo método de imersão pelo princípio de Arquimedes (norma ABNT-NBR6620). As caracterizações físicas e microestruturais foram feitas por difração de raios X (difratômetro Siemens D-5005) e microscopia eletrônica de varredura (Philips XL-30 FEG) em amostras cortadas e polidas. $\mathrm{O}$ ataque térmico, aplicado nas amostras após o polimento, teve taxa de aquecimento controlada, de acordo com o tipo de sinterização, e aquecimento até $50^{\circ} \mathrm{C}$ abaixo da temperatura de sinterização, com patamar de $12 \mathrm{~min}$.

\section{RESULTADOS E DISCUSSÃO}

Inicialmente foi realizado o estudo da sinterização convencional, visando o entendimento do efeito da temperatura de sinterização do compósito mulita-cordierita nas amostras com características físicas e químicas específicas utilizadas nesta pesquisa. As variáveis da sinterização selecionadas foram de acordo com estudos clássicos realizados com materiais similares reportados na literatura. A Fig. 1 apresenta os resultados de densidade relativa das amostras sinterizadas em forno convencional de $1300{ }^{\circ} \mathrm{C}$ a $1500{ }^{\circ} \mathrm{C}$ com patamar de $2 \mathrm{~h}$.

Os resultados mostram uma tendência ascendente na densidade relativa com o aumento da temperatura de 


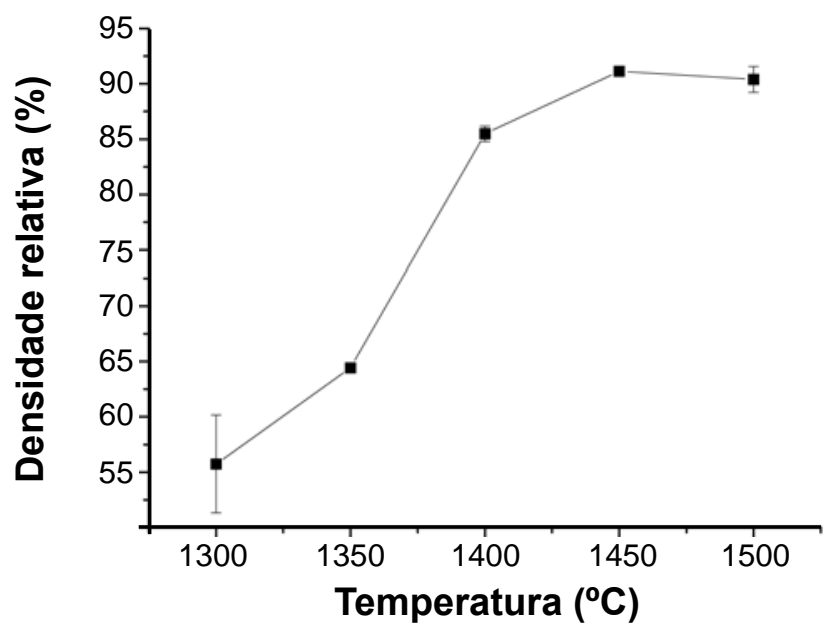

Figura 1: Densidade relativa das amostras sinterizadas em forno convencional.

[Figure 1: Relative density of samples sintered in a conventional oven.]

sinterização até um pico em $1450{ }^{\circ} \mathrm{C} / 2 \mathrm{~h}$, com uma ligeira queda posterior a $1500{ }^{\circ} \mathrm{C} / 2 \mathrm{~h}$. Essa ascendência se deve ao aumento da cinética do processo de sinterização, fortemente influenciado pelos mecanismos de densificação relacionados ao processo de sinterização via fase líquida, fase esta originada pelo aumento da temperatura no compósito mulitacordierita. Por outro lado, a diminuição da densidade relativa a $1500{ }^{\circ} \mathrm{C} / 2 \mathrm{~h}$, também verificada por Mussler e Shafer [16] em amostras de compósito de mesma proporção de fase do analisado neste trabalho, ocorreu devido ao fenômeno de formação de uma fase gasosa acima de $1455{ }^{\circ} \mathrm{C}$, fato que acarretou alteração na densificação e no tamanho do poro do compósito, como exposto nas constatações dos autores. A partir desses resultados, é possível observar os efeitos da sinterização no estado sólido e líquido: a sinterização no estado sólido acontece até $1400{ }^{\circ} \mathrm{C}$ e $1450{ }^{\circ} \mathrm{C}$, a partir da qual começa a ocorrer a sinterização via fase líquida devido à formação de uma fase líquida rica $\mathrm{em} \mathrm{SiO}_{2}$ contendo $\mathrm{MgO}$, originária da cordierita.

A Fig. 2 apresenta os resultados obtidos por difração de raios X. A fase cordierita diminuiu com o aumento da temperatura de sinterização, não sendo mais observada a $1500{ }^{\circ} \mathrm{C} / 2 \mathrm{~h}$, e ocorre aumento da fase mulita na temperatura de $1500^{\circ} \mathrm{C}$.

A diminuição e ausência dos picos referentes à fase cordierita se devem ao fato de que a cordierita se desestabiliza quimicamente à medida que a temperatura aumenta. Com esta desestabilização, o MgO, originário desta fase, começa a interagir com o $\mathrm{SiO}_{2}$, principalmente o originário desta mesma fase, formando uma fase líquida rica em $\mathrm{SiO}_{2}$ contendo $\mathrm{MgO}$ a partir da faixa de temperatura de $1410{ }^{\circ} \mathrm{C}$ a $1425^{\circ} \mathrm{C}[3,8$, 17]. A elevação da temperatura gera maior desestabilização, originando maior quantidade de $\mathrm{MgO}$ que, por sua vez, interage mais com o $\mathrm{SiO}_{2}$. Isso se dá até a fusão completa da fase. Essa fase líquida formada tende a se vitrificar durante o resfriamento, devido à taxa à qual esta fase é submetida, mantendo assim uma estrutura desorganizada no estado sólido

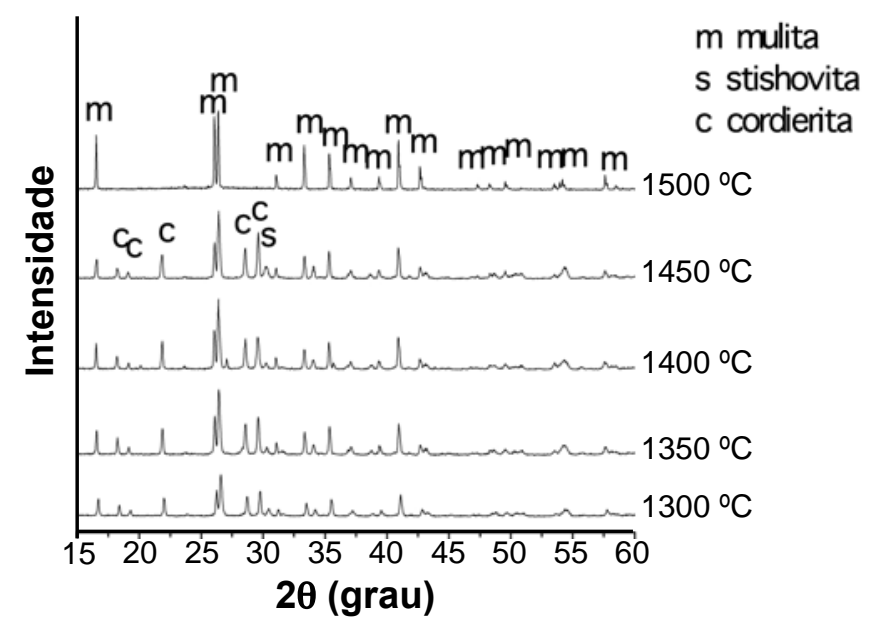

Figura 2: Difratogramas de raios $\mathrm{X}$ das amostras sinterizadas em forno convencional.

[Figure 2: XRD patterns of samples sintered in the conventional oven.]

e, portanto, não apresenta picos característicos quando analisados por difração de raios $\mathrm{X}$. O pequeno aumento dos picos referentes à fase mulita deve-se à cristalização da fase mulita durante o resfriamento do material sinterizado a $1500{ }^{\circ} \mathrm{C} / 2 \mathrm{~h}$. $\mathrm{O}$ ponto referente à composição do material utilizado no presente estudo se encontra na área de cristalização da mulita, caso analisemos o diagrama de equilíbrio $\mathrm{SiO}_{2}-\mathrm{MgO}-\mathrm{Al}_{2} \mathrm{O}_{3}$ referente à temperatura de $1500{ }^{\circ} \mathrm{C}$. Vale a pena ressaltar que resultados similares foram reportados por Camerucci [18].

A Fig. 3 apresenta os resultados obtidos por microscopia eletrônica de varredura das amostras sinterizadas em forno convencional a $1450{ }^{\circ} \mathrm{C} / 2 \mathrm{~h}$ e $1500^{\circ} \mathrm{C} / 2 \mathrm{~h}$.

$\mathrm{Na}$ Fig. 3a é possível observar o aspecto geral da amostra que obteve maior densidade aparente (91\%). Nela é possível destacar a uniformidade pela qual os poros estão distribuídos, sem presença de bolhas, embora ocorra a presença de fase vítrea, conforme foi discutido anteriormente, além do aspecto uniforme, que evidencia uma homogeneidade da microestrutura. Na Fig. 3b observam-se nitidamente bolhas na superfície das amostras, que resultam do borbulhamento e geração de gás devido à decomposição da cordierita em forsterita e mulita. Estas bolhas mostram o aprisionamento do gás, diminuindo a densidade relativa correspondente, conforme discutido na Fig. 1.

A Fig. 4 apresenta as densidades relativas das amostras sinterizadas por sinterização ultrarrápida em forno de microondas. Nela foi possível observar o acréscimo da densidade com o aumento da potência do forno, e sua dependência com o tempo de sinterização de 20 e 30 min.

Os gráficos mostram uma tendência ascendente na densidade com o aumento da potência, que está diretamente relacionada com a temperatura de sinterização. Esse comportamento é seguido pelo decréscimo da densidade com o aumento da potência, com tempo de sinterização $30 \mathrm{~min}$. Essa queda da densidade observada nas amostras sinterizadas a $2,1 \mathrm{~kW}$ por 30 min de patamar teve o mesmo comportamento 

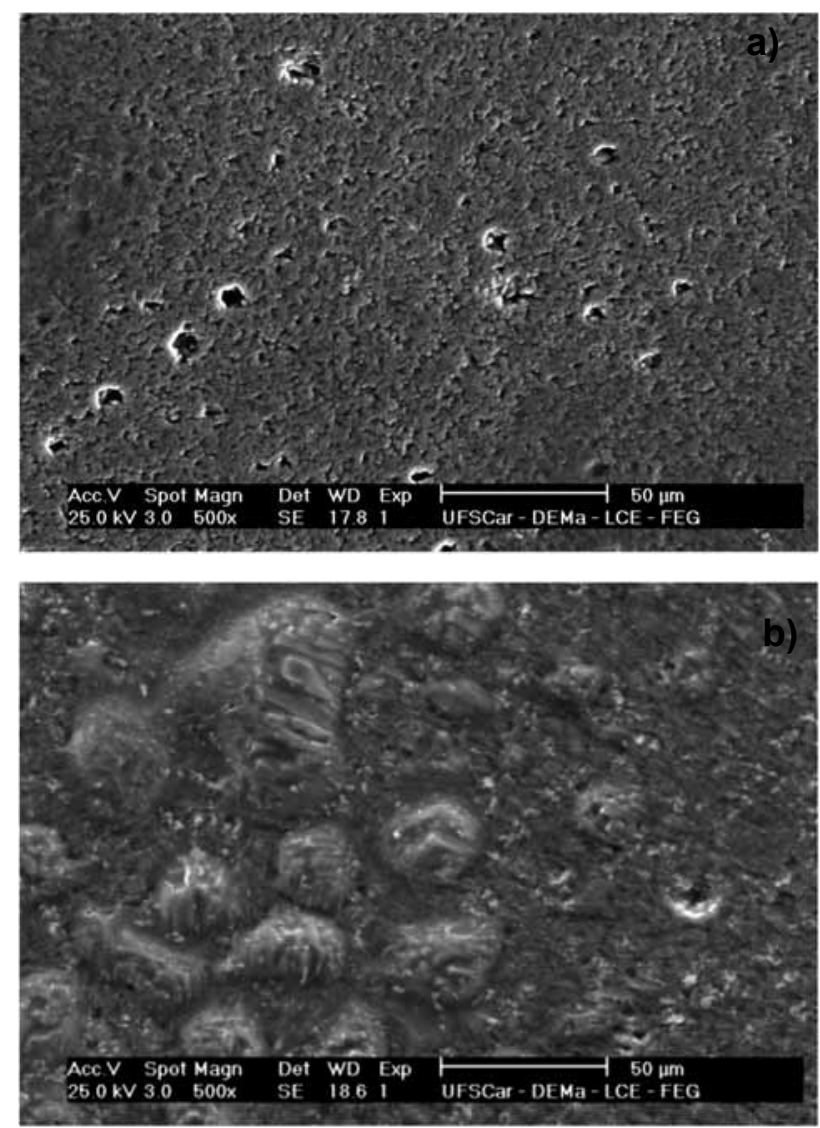

Figura 3: Micrografias (microscopia eletrônica de varredura) das amostras sinterizadas em forno convencional em $1450{ }^{\circ} \mathrm{C}$ (a) e $1500{ }^{\circ} \mathrm{C}(\mathrm{b})$.

[Figure 3: SEM micrographs of samples sintered in conventional oven at $1450{ }^{\circ} \mathrm{C}$ (a) and $\left.1500{ }^{\circ} \mathrm{C}(\mathrm{b}).\right]$

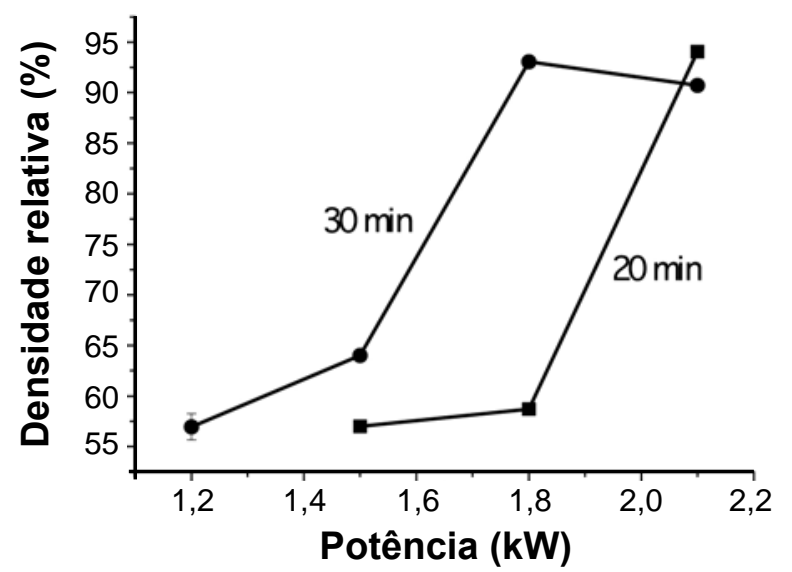

Figura 4: Densidade relativa das amostras sinterizadas em forno de micro-ondas.

[Figure 4: Relative density of microwave sintered samples.]

observado das amostras sinterizadas em forno convencional acima de $1450{ }^{\circ} \mathrm{C}$, implicando que nessas condições e num tempo extremamente pequeno de sinterização (30 min), comparado com o do forno convencional (410 $\mathrm{min})$, os resultados se assemelham. As Figs. 5 e 6 apresentam os resultados por difração de raios $\mathrm{X}$ das amostras sinterizadas

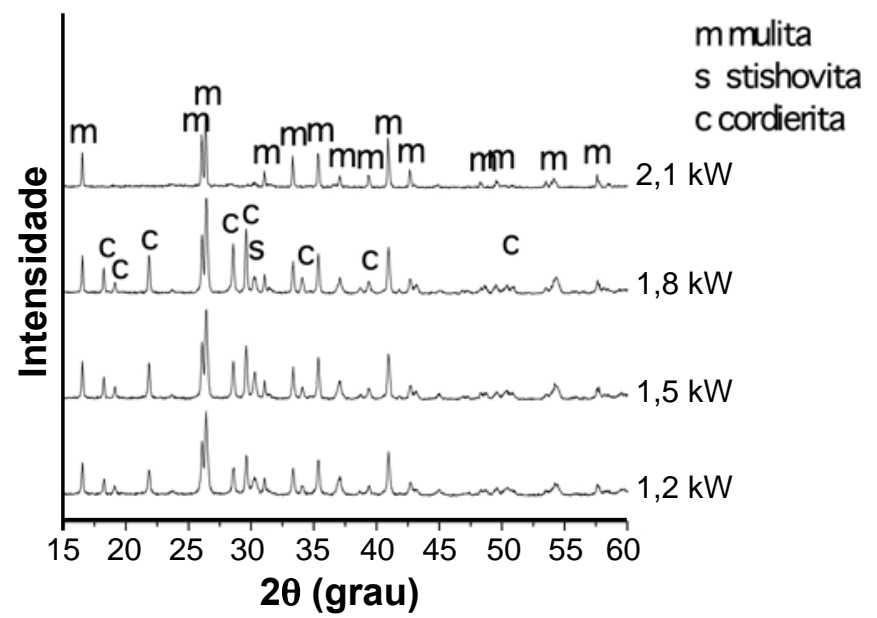

Figura 5: Difratogramas de raios $\mathrm{x}$ das amostras sinterizadas em forno de micro-ondas por $20 \mathrm{~min}$.

[Figure 5: XRD diffraction patterns of samples sintered in the microwave oven for $20 \mathrm{~min}$.]

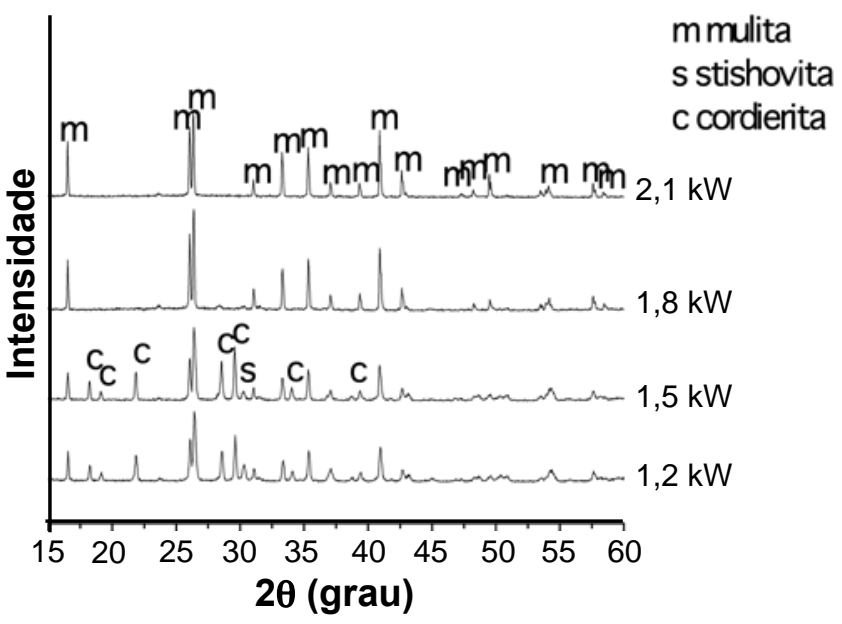

Figura 6: Difratogramas de raios $\mathrm{x}$ das amostras sinterizadas em forno de micro-ondas por $30 \mathrm{~min}$.

[Figure 6: XRD diffraction patterns of samples sintered in the microwave oven for $30 \mathrm{~min}$.]

por micro-ondas em 20 min e $30 \mathrm{~min}$, respectivamente.

Nos resultados obtidos das amostras sinterizadas com apenas 20 min de patamar observou-se a mesma tendência de formação de fase vítrea acima de $1,8 \mathrm{~kW}$, como discutido nas amostras sinterizadas em forno convencional, Fig. 2. Com o aumento do tempo de patamar, passando de 20 para 30 min, a formação dessa fase vítrea ocorreu já nas amostras sinterizadas em potência de $2,1 \mathrm{~kW}$. Comprova-se assim que os efeitos de transformação de fases de cristalina para vítrea em condições severas de sinterização, como observados na sinterização ultrarrápida por micro-ondas, em tempos bem inferiores aos normalmente observados numa sinterização convencional. A Fig. 7 apresenta as micrografias das amostras sinterizadas por micro-ondas nas condições de $2,1 \mathrm{~kW}$ e $30 \mathrm{~min}$ e $2,1 \mathrm{~kW}$ e $20 \mathrm{~min}$.

Observou-se na Fig. 7a que existe uma fase vítrea que banha a superfície dos grãos de mulita e bolhas na superfície 

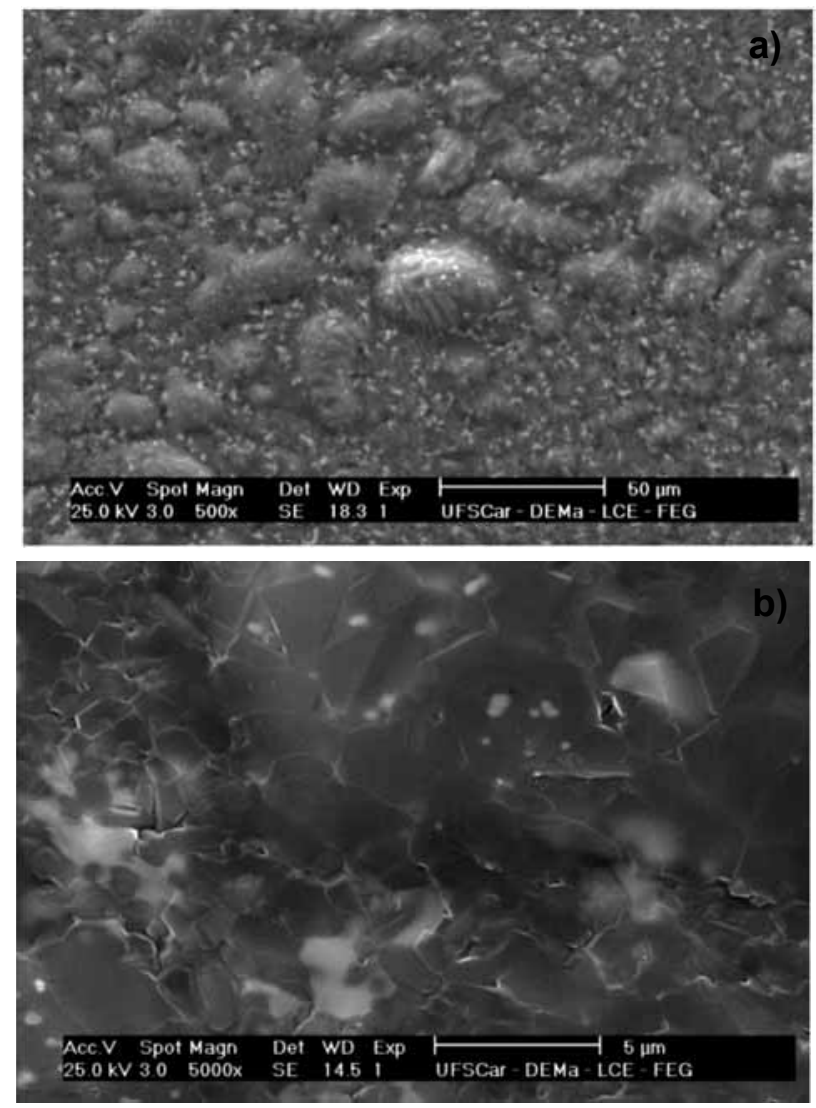

Figura 7: Micrografias (microscopia eletrônica de varredura) das amostras sinterizadas em forno de microondas em $2,1 \mathrm{~kW}$ por $30 \min ($ a) e $2,1 \mathrm{~kW}$ por $20 \mathrm{~min}$ (b).

[Figure 7: SEM micrographs of samples sintered in the microwave oven: (a) at $2.1 \mathrm{~kW}$ for $30 \mathrm{~min}$, and (b) at $2.1 \mathrm{~kW}$ for $20 \mathrm{~min}$.]

da fratura, de forma semelhante à apresentada na amostra sinterizada convencionalmente a $1500{ }^{\circ} \mathrm{C}$, presente na Fig. $3 \mathrm{~b}$, porém com a diferença de que, neste caso, as bolhas se apresentam em maior quantidade e em tamanhos menores. $\mathrm{Na}$ Fig. 7b, cujo aumento é maior que o da Fig. 7a, podem-se observar claramente os contornos de grãos de mulita e a fase vítrea. É interessante ressaltar que, com a redução de $10 \mathrm{~min}$ de patamar de sinterização nessa mesma potência, conforme resultados da Fig. 7a, o compósito não apresentou mais a presença de bolhas, permitindo, nesse caso, concluir que o tempo de patamar de sinterização foi também um parâmetro de sinterização extremamente importante a ser controlado. Assim, os ajustes da taxa de aquecimento, potência e do tempo de patamar de sinterização foram imprescindíveis para o controle final da microestrutura da amostra, evitando-se assim formação de bolhas. Na potência de $2,1 \mathrm{~kW}$ e tempo de patamar de 20 min foi a condição de sinterização por microondas onde o compósito mulita-cordierita apresentou maior densidade relativa (94\%) sem presença de bolhas.

\section{CONCLUSÕES}

É possível sinterizar por sinterização ultrarrápida em micro-ondas compósitos de mulita-cordierita. O tempo necessário para sinterizar os compósitos no forno convencional foi de $120 \mathrm{~min}$ de patamar para se atingir a maior densidade relativa de $91 \%$, enquanto que no forno de micro-ondas foi de apenas 20 min de patamar e a densidade relativa foi de $94 \%$. Os efeitos da fase líquida, observados na sinterização ultrarrápida em micro-ondas, foram idênticos aos observados pela sinterização convencional. A diminuição da densidade relativa mostra que houve formação de gás decorrente da decomposição da cordierita e formação de bolhas na superfície do compósito sinterizado.

\section{AGRADECIMENTOS}

Os autores agradecem à FAPESP (Proc. 07/59564-0) pelo apoio financeiro e ao CNPq pelas bolsas (113749/20082), CAPES (PNPD 02681/09-9) e à empresa Scimarec Co., Japão, pela doação das amostras de mulita-cordierita.

\section{REFERÊNCIAS}

[1] I. A. Aksay, D. M. Dabbs, M. Sarykaya, J. Am. Ceram. Soc. 74 (1991) 2343-2358.

[2] M. D. Sack, H-W. Lee, J. Pask, Ceram. Trans. 6 (1990) 167-207.

[3] V. Viswabaskaran, F. D. Gnanam, M. Balasubramanian, J. Mater. Proc. Technol. 142 (2003) 275-281.

[4] J. R. Casarini, Cerâmica 26 (1980) 143-156.

[5] M. A. P. Jordão, J. Manzo, F. B. Angeleri, Cerâmica 20 (1974) 297-304.

[6] J. D. Hodge, Adv. Ceram. 19 (1987) 117-129.

[7] P. M. Souto, R. R. Menezes, R. H. G. A. Kiminami, Ceram. Int. 37 (2011) $24-248$.

[8] L. Montanaro, C. Perrot, C. Esnouf, G. Thollet, G. Fantozzi, A. Negro, J. Am. Ceram. Soc. 83 (2000) 189-96.

[9] E. T. Thostenson, T. W. Chou, Microwave processing: fundamentals and applications, Composites: Part A 30 (1999) 1055-1071.

[10] P. M. Souto, R. R. Menezes, R. H. G. A. Kiminami, J. Mater. Proc. Technol. 209 (2009) 548-553.

[11] P. M. Souto, R. R. Menezes, R. H. G. A. Kiminami, Cerâmica 53, 325 (2007) 1-10.

[12] P. M. Souto, R. R. Menezes, R. H. G. A. Kiminami, Cerâmica 53, 326 (2007) 108-115.

[13] P. M. Souto, R. R. Menezes, R. H. G. A. Kiminami, Cerâmica 53, 327 (2007) 218-226.

[14] R. R. Menezes, P. M. Souto, R. H. G. A. Kiminami, Microwave Fast Sintering of Ceramic Materials in Sintering of Ceramics -New Emerging Techniques, In Tech., Croatia (2012) p.3.

[15] W. H. Sutton, Am. Ceram. Soc. Bull. 68 (1989) 376-386. [16] B. H. Mussler, M. W. Shafer, Am. Ceram. Soc. Bull. 63 (1984) $705-710$.

[17] M. G. M. U. Ismail, H. Tsunatori, Z. Nakai, J. Mater. Sci. 25 (1990) 2619-2625.

[18] M. A. Camerucci, G. Urretavizcaya, A. L. Cavalieri, Ceram. Int. 29 (2003) 159-168.

(Rec. 03/05/2012, Ac. 08/06/2012) 